Received: December 5, 2017

Revision received: June 8,2018

\title{
Research on Innovative Methods of College Students' Sports Teaching Based on Internet Education Technology
}

\author{
Ke Ren ${ }^{1}$ \\ Northeastern University
}

\author{
Ying $\mathrm{Bai}^{2}$ \\ Northeastern University
}

\begin{abstract}
With the development of science and technology, the concept of Internet has been integrated into daily life. The blowout growth of intelligent mobile terminals and the rapid coverage of wireless networks are also the growth points of stimulating the Internet. The convenience factors brought by the Internet make it an indispensable part of life. With its convenience, APP has become a bridgehead for the combination of the Internet and our lives. Similarly, under the mode of "Internet +", the sports of colleges and universities has also ushered in a new development opportunity. Through APP, the sports of colleges and universities is carried out to make up for the unilateral pursuit of sports behavior while neglecting the attitude, consciousness and values of sports as well as the problem that the unified teaching cannot meet the needs of the differences of college students.
\end{abstract}

\section{Keywords}

Internet Education • College Students • Sports

\footnotetext{
${ }^{1}$ Correspondence to: Ke Ren (MA), Department of Physical Education, Northeastern University, Shenyang 110000, China. Email: Rbying1314@163.com

${ }^{2}$ Department of Physical Education, Northeastern University, Shenyang 110000, China. Email: 9535078@qq.com

Citation: Ren, K., Bai, Y., Research on Innovative Methods of College Students' Sports Teaching Based on Internet
Education Technology. Educational Sciences: Theory \& Practice, 18(5), 2486-2493.
http://dx.doi.org/10.12738/estp.2018.5.149
}


The "Internet $+"$ stems from the idea of combining the Internet (Omicini \& Zambonelli, 1999) with traditional industries in the 2015 work report government delivered by Premier Li Keqiang. "+" represents all walks of life in the traditional industry, just like "Internet + " cross-border integration, connecting all the characteristics and forming a number of representative new configurations, gradually permeating and radiating from the initial layout of the tertiary industry such as Internet traffic and Internet medicine (Hubbs, Rindfleisch, Godin \& Melmon, 1997; Glowniak \& Glowniak, 1995) to the primary and secondary industries. The role of the Internet in various industries has also changed from the original "facilitator" to the "leader". The "Internet +" compared to the Internet (Ozer, 2003) includes new elements as shown in the following figure.

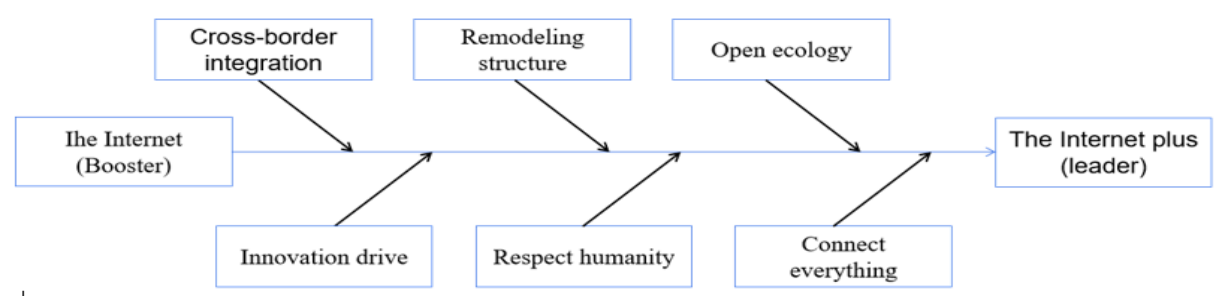

Figure 1. New elements of the Internet plus.

\section{Sports}

The concept of physical behavior is quite extensive, and sports-related activities can be basically referred to as physical behavior, but the definition of sports (Hardman, 2008; Bailey, 2010) is relatively narrow. Sports in colleges and universities (Sullivan et al., 2008) basically relies on a few sports classes to teach some basic movement knowledge, such as basic methods to avoid movement damage, and basic sports rules. Although some colleges and universities have satisfied the college students' desire to choose the sports course independently, the actual survey data show that the sports in colleges and universities (Nahas, Goldfine \& Collins, 2003) is still not recognized by the college students. In sports science, sports are defined from many angles. Sports behavior includes sports behavior, sports attitude, sports consciousness and sports consumption behavior, and the influence of sports on individuals is carefully divided, as shown in Figure 2.

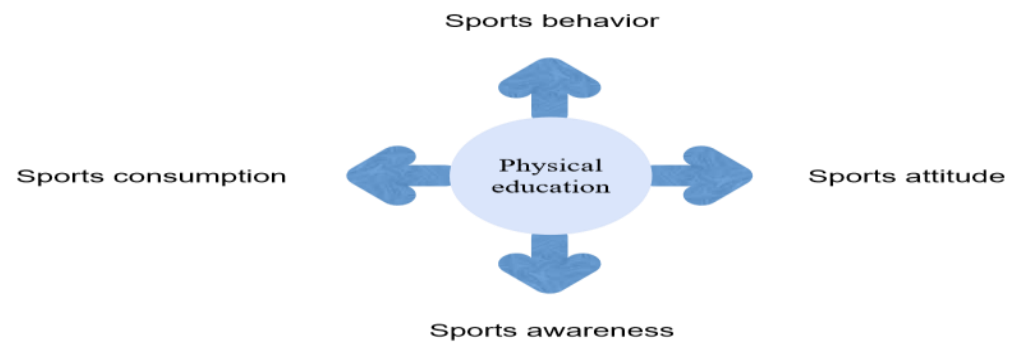

Figure 2. The impact of sports on individuals. 
Ren, Bai / Research on Innovative Methods of College Students' Sports Teaching Based on Internet Education Technology

The aspects related to sports attitude, values, demands and motives are often not reflected in the education of colleges and universities. This is also the reason for the low recognition of college sports by college students, without inspiring college students to love sports activities.

\section{Combination of "Internet +" and Physical Education}

The combination of "Internet +" and any traditional industry (Caseber, Bennett, Kristofco, Carillo \& Centor, 2002) is not a superposition of simple answers. With the development of China's economy and society, the blowout growth of intelligent mobile equipment and the rapid development of China's wireless network, the Internet has been closely integrated with all aspects of life. And each kind of APPs also enjoys blowout growth, with the field expanding unceasingly, for serving our daily life better. College students are one of the people who have the courage to create and accept new things. Therefore, in the wave of Internet, college students can feel the convenience of "Internet + " in every aspect more acutely. Under the background of the times, the combination of "Internet + " and sports education creates new opportunities and new challenges for the development of the reform of sports in colleges and universities in China (Jianjun \& Huping, 2001 \& Madon, 2000).

\section{Research and Methods on the Present Situation of College Students' Sports Activities}

In order to more accurately obtain the present situation of contemporary college students' daily sports, a questionnaire survey is carried out to survey some college students in a university. In order to ensure that the proportion of men and women in the surveyed college is adequate and that the special college (such as sports college) is not representative of the overall college students, a questionnaire is sent out by both the automation college and the law school. In this study, 1,036 questionnaires are distributed to the students of the two colleges. 951 questionnaires are collected, and the effective rate is about $92 \%$. The number and gender distribution of students in the two colleges are shown in the following table (1).

Table 1

Questionnaire Basic Information

\begin{tabular}{llcc}
\hline Basic Information & Gender & Questionnaires issued & Valid questionnaires \\
\hline \multirow{2}{*}{ Automation college } & Male & 267 & 244 \\
& Female & 245 & 223 \\
Faculty of law & Male & 254 & 236 \\
& Female & 270 & 248 \\
\hline
\end{tabular}

\section{Results and Analysis}

\section{Basic situation analysis}

After sorting out the effective questionnaires, the difference between the ratio of men to women and the total number of students in arts and sciences is basically in line with the expectation, which ensures the credibility, scientificity and rationality of the questionnaire. College students who hold smartphones and use sports APPs are shown in Tables 2 and 3 below. The results show that more than $99 \%$ of students have 
smartphones, and more than $50 \%$ of college students know and are using one or more APPs to help or assist themselves in sports and record health data.

Table 2

Survey of Status of College Students with Smartphones

\begin{tabular}{lcc} 
& & Nes \\
\hline Number of People & 948 & 3 \\
Percentage & $99.68 \%$ & $0.32 \%$ \\
\hline
\end{tabular}

Table 3

Survey Form of College Students Using Sports App

\begin{tabular}{lccc}
\hline & Do not know & Know but not used & Using \\
\hline Number of People & 120 & 231 & 597 \\
Percentage & $12.7 \%$ & $24.4 \%$ & $62.9 \%$ \\
\hline
\end{tabular}

\section{Analysis of the intensity and frequency of daily sports}

The intensity and frequency of physical exercise will directly affect the effect of exercise. The frequency of exercise plays an important role in college students developing habit of exercise, and the intensity of exercise is also essential to the maintenance of physical health. All these are the key indexes to evaluate college students' participation in sports. The results of the questionnaire on the frequency and intensity of college students' daily sports activities are shown in Figures 3 and 4.

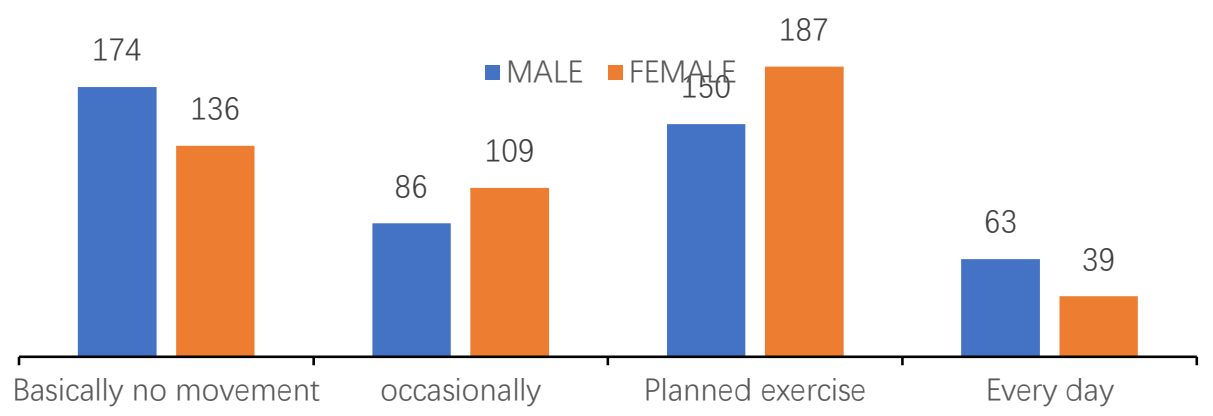

Figure 3. Frequency of college students participating in the questionnaire.

As can be seen from the statistical results of the daily activity frequency of college students, there is little difference in the habits of boys and girls, two-thirds of girls and boys have daily sports, and among students with sports, there are the largest number of students with planned sports and the least number of students participating in sports every day. 


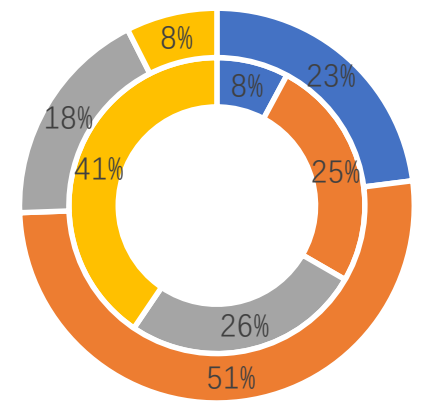

- Low intensity

- Slight sweating

- Medium perspiration

- Sweaty and sweating

Figure 4. The intensity of college students participating in the questionnaire.

Figure 4 shows the intensity statistics of boys and girls participating in sports in both sides. The overall sports situation of girls tends to be mild, while the high-intensity sports of boys account for a higher proportion, which is consistent with the actual situation.

\section{Analysis on motivation of using sports APPs}

In the questionnaire survey, the sports APPs downloaded by the students of the two colleges themselves are counted. Most of the students downloaded more than one APP.

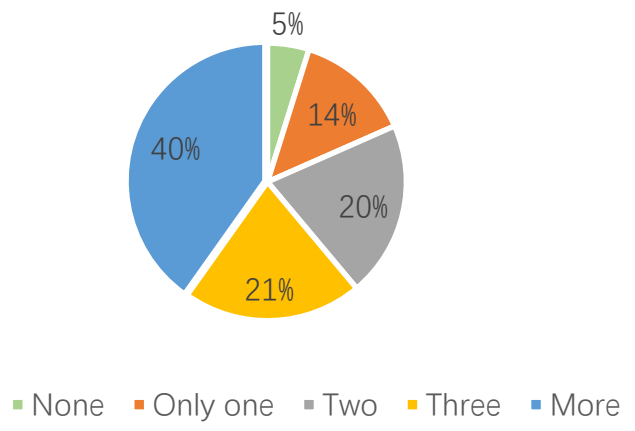

Figure 5. Number of sports apps downloaded from college students' mobile phones.

With the progress of society, more and more kinds of sports come into our vision, but the traditional physical education in colleges and universities cannot include all sports, especially some new sports. However, there are some personal tutorials in APPs that individuals can find for themselves to participate in support activities for a sporting event. Plus, a lot of APP accounts associated with Wechat and Weibo accounts with social elements, it's more popular for college students to find like-minded friends or work with friends in sports. 


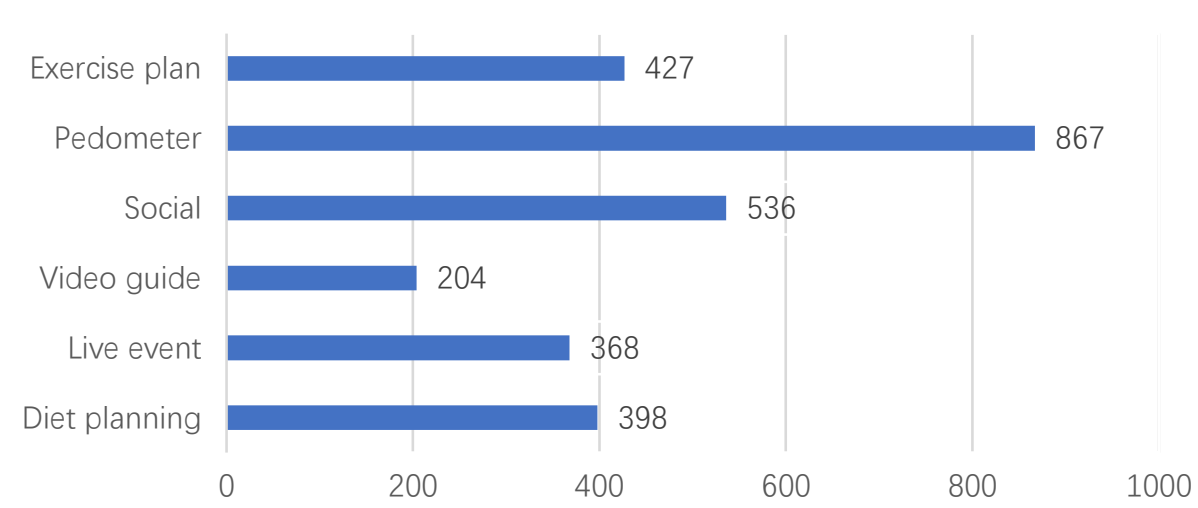

Figure 6. College students use sports APP activities.

\section{Disadvantages of sports APPs}

Based on the above questionnaire survey, the current situation of college students' sports, combined with sports education model research under the "Internet + " mode. The popularization of intelligent mobile equipment enables college students to involve in the Internet anytime and anywhere, which also stimulates the development of a series of sports APPs, and is a good carrier for improving sports education in colleges and universities. However, there are still some problems in using APPs to promote sports education in colleges and universities.

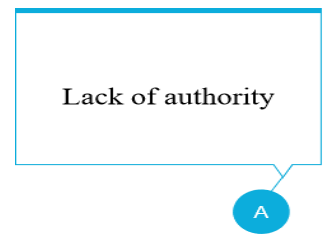

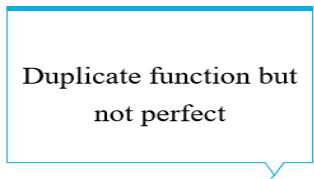

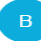

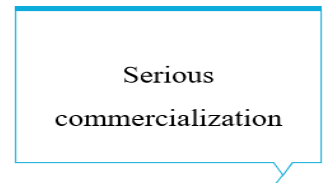

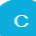

Figure 7. Current problems in sports APP.

First of all, there are many kinds of sports APPs with uneven level and non-professional guidance on some sports, which may not be able to achieve standard and accurate guidance for beginners, and even cause some sports damage, and attack the enthusiasm of beginners. Although there are many kinds of APPs at present, each APP function is not perfect, which is one of the reasons why most college students have installed several APPs.

\section{Conclusion}

\section{"Internet +" sports education mode is a new turning point of sports education in colleges and universities}

Sports APPs are widely used by surveyed students from both colleges, which is a good platform for sports education in colleges and universities, and these college students voluntarily accept APPs based on their own 
sociability. With high degree of freedom among college students, sports APPs as whole have a positive effect on the sports activities of college students. Secondly, sports education through APPs is also helpful to alleviate the problem of unbalanced education so that the national college students can enjoy high-level sports education together. The sports education in colleges and universities should explore a new physical education mode in colleges and universities using APPs as a platform, and in addition to the sports education classes, they bring some education that transcends the sports behavior such as sports spirit and values.

\section{The use of APPs for sports education still needs further exploration}

The reform of sports education in colleges and universities by using "Internet +" mode or sports APPs is still at the conceptual stage, and there are still many problems, such as the low threshold of speech of various sports APPs. What's more, beginners often do not have the ability to judge the pros and cons, which may attack beginners' enthusiasm for learning and even cause sports damage, so a unified and authoritative platform needs more sports education experts to build together and a completely functional APP needs to be made to reduce the downloading of multiple homogenous APPs.

\section{References}

Bailey, R. (2010). Sports and sport in schools: A review of benefits and outcomes. Journal of School Health, 76(8), 397-401.

Casebeer, L., Bennett, N., Kristofco, R., Carillo, A., \& Centor, R. (2002). Physician internet medical information seeking and on-line continuing education use patterns. Journal of Continuing Education in the Health Professions, 22(1), 33-42.

Glowniak, J. V., \& Glowniak, J. V. (1995). Medical resources on the internet. Annals of Internal Medicine, 123(2), 123.

Hardman, K. (2008). Sports in schools: A global perspective. Kinesiology, 40(1), 5-28.

Hubbs, P. R., Rindfleisch, T. C., Godin, P., \& Melmon, K. L. (1997). Medical information on the internet. Journal of General Internal Medicine, 12(8), 466-470.

Jianjun, L., \& Huping, C. (2001). A review on the research work of sports consumption in China. Sports \& Science, 6, 337-343.

Madon, S. (2000). The internet and socioeconomic development: exploring the interaction. Information Technology \& People, 13(2), 85-101. http://dx.doi. org/10.1108/09593840010339835

Nahas, M. V., Goldfine, B., \& Collins, M. A. (2003). Determinants of physical activity in adolescents and young adults: The basis for high school and college sports to promote active lifestyles. Physical Educator, 60(1), $42-56$.

Omicini, A., \& Zambonelli, F. (1999). Coordination for internet application development. Autonomous Agents and Multi-Agent Systems, 2(3), 251-269.

Ozer, M. (2003). Process implications of the use of the internet in new product development: A conceptual analysis. Industrial Marketing Management, 32(6), 517-530. http://dx.doi. org/10.1016/S00198501(02)00276-6 
Ren, Bai / Research on Innovative Methods of College Students' Sports Teaching Based on Internet Education Technology

Sullivan, S. L., Keating, X. D., Chen, L., Guan, J., Delzeitmcintyre, L., \& Bridges, D. (2008). Sports and general health courses and minority community college student risk levels for poor health and leisure-time exercise patterns. College Student Journal, 42, 132-151. 